\title{
EDUCAÇÃO AMBIENTAL: EXPERIÊNCIAS A PARTIR DA IMPLANTAÇÃO DE HORTAS ESCOLARES
}

Igor Georgios Fotopoulos ${ }^{1}$ Jeferson Alberto de Lima ${ }^{2}$ Gabriel Araújo Paes Freire ${ }^{3}$ André Procópio Lima Silva ${ }^{4}$ Avilyn Barbara Garcia Lopes ${ }^{5}$ Nayara dos Santos Albrigo ${ }^{6}$

Resumo: Esse trabalho tem como objetivo difundir a implantação de hortas escolares por meio de procedimentos plausíveis à realidade socioambiental brasileira, sobretudo da região amazônica, para o cumprimento da Lei no 9.725/1999. Em vista disso, foram realizadas atividades teóricas e práticas no âmbito escolar, capazes de estimular nos alunos desempenhos apropriados as temáticas ambientais. Entre os resultados, destacam-se os meios alternativos de aprendizagem a partir do cultivo de espécies oleráceas em escolas públicas do município de Ji-Paraná/RO. Com base nesse estudo, foi possível evidenciar que no território amazônico há necessidade de formular novas maneiras para estimular o conhecimento em benefício da Educação Ambiental.

Palavras-chave: Percepção Ambiental; Olericultura Escolar; Sustentabilidade.

Abstract: This work has as objective to diffuse the implementation of the edible school gardens through plausible proceedings to the Brazilian socio-environmental reality, mainly from the Amazon region, for the enforcement of the law no 9.725/1999. In view of this, theoretical and practical activities were realized at school ambit, able to stimulate in the students the proper performance in environmental themes. Among the results, stands out the alternative means of learning from the cultive of the oleraceous species in public schools in the municipality of Ji-Paraná/RO. Based on this study, it was possible to demonstrate that in the Amazon territory there is the need to formulate new ways to stimulate knowledge for the benefit of Environmental Education.

Keywords: Environmental Perception. School Olericulture. Sustainability.

${ }^{1}$ Universidade Federal de Rondônia. E-mail: fotopoulos@unir.br.

2 Universidade Federal de Rondônia. E-mail: jeferson.lima@unir.br

3 Universidade Federal de Rondônia. E-mail: paesfreire@gmail.com

${ }^{4}$ Universidade Federal de Rondônia. E-mail: andreprocopio.ea@gmail.com

5 Universidade Federal de Rondônia. E-mail: avilyn_lira@hotmail.com

6 Universidade Federal de Rondônia. E-mail: nayara.santosalbrigo95@gmail.com

Revbea, São Paulo, v.16, № 1: 378-392, 2021. 


\section{Introdução}

O progresso das civilizações gerou intensas mudanças no uso e na cobertura da terra, causando consequências para o desequilíbrio dos ecossistemas naturais e a necessidade de modelos menos impactantes sobre a perspectiva ambiental.

Em vista disto, especial atenção tem sido dada para países em desenvolvimento socioeconômico, onde a produção de divisas provém de severos distúrbios no ambiente e do uso indiscriminado de agrotóxicos, sendo estes prejudiciais à biodiversidade e à saúde humana (RODRIGUES et al., 2019; SILVA et al., 2019).

No cenário global, o Brasil se destaca pelo agronegócio, mas acumula sérios problemas na relação homem-natureza, em especial porque uma parcela significativa da sociedade enxerga o ambiente apenas como via de exploração dos recursos. Neste sentido, é de extrema relevância a prioridade de mudanças, sobretudo de juízo da sociedade para uso racional dos recursos naturais e dos benefícios ecológicos disponibilizados pelo meio ambiente.

Uma maneira de reverter as práticas nocivas e exploratórias do homem sobre a natureza é através da Educação Ambiental (EA), a qual possibilita a transformação do indivíduo a partir da conscientização dos cuidados com o meio ambiente (JACOBI, 2013). Baseado nisto, a participação do cidadão na construção de novos saberes frente a problemas contemporâneos faz com que ocorram transformações culturais no que diz respeito às questões sociais, ambientais e econômicas (ROCHA et al., 2013).

Diante de tais circunstâncias, a Educação Ambiental visa idealizar novos conceitos com o propósito de favorecer a percepção ambiental através da sensibilização do sujeito. Para tanto, a EA dispõe de um conjunto de processos em que o indivíduo, juntamente com a coletividade, é capaz de prover distintos conhecimentos e valores para a conservação do meio ambiente, tal como propõe as Diretrizes Curriculares Nacionais para Educação Ambiental, de 15 de junho de 2012.

Todavia, a EA vem sendo difundida desde 1999 no Brasil com o estabelecimento da Lei no 9.725, a qual institui a Política Nacional de Educação Ambiental e ordena que esta seja implantada em todos os níveis do ensino formal da educação brasileira. Por conta disto, alternativas práticas da EA têm sido difundidas no país e, na maioria das vezes, o ser humano é induzido a ter contato com o meio ambiente de maneira lúdica.

Assim, a implantação da olericultura nas escolas pode ser exercida em prol da EA, sobretudo porque essa prática de horticultura engloba diversas espécies comestíveis, com ciclos de vidas curtos e que não necessitam de grandes espaços para cultivo (HENNIG; LENARDÃO, 2016). Neste contexto, as culturas oleráceas funcionam como um canal para que os alunos interajam diretamente com o meio, de tal modo que possam ampliar a capacidade de aprendizagem por intermédio de um laboratório didático alternativo, onde 
docentes e discentes tem a capacidade de contextualizar os conteúdos teóricos abordados nas disciplinas de forma trans e interdisciplinar, tornando os ensinamentos mais atrativos.

Porém, vale lembrar que a EA deve ser abrangida de maneira permanente, contínua e crescente, conforme as fases do ensino formal da educação brasileira. Ademais, é necessário que a EA envolva contextos históricos e sociais, bem como diversas áreas do conhecimento, para a participação efetiva da sociedade (ROSA et al., 2010; MINÉU et al., 2014; SANTO et al., 2019).

Por todo o exposto, o presente trabalho tem como objetivo apresentar os procedimentos adotados na implantação de hortas escolares, com o desígnio de operarem como alternativas didáticas para o cumprimento da Política Nacional de Educação Ambiental. Neste ponto, destaca-se que o estudo é resultado do projeto de extensão universitária intitulado: Olericultura Escolar: Educação Ambiental, Sustentabilidade e Cidadania, o qual contou com uma equipe de professores, técnicos e alunos da Fundação Universidade Federal de Rondônia - UNIR, no período de dezembro de 2015 a dezembro de 2016.

\section{Metodologia}

\section{Área de estudo}

O projeto foi desenvolvido no município de Ji-Paraná, região localizada na parte central do estado de Rondônia, onde selecionou-se para estudo duas escolas públicas, sendo uma estadual situada na área urbana, e outra municipal situada na zona rural (Figura 1). Tais unidades de ensino foram descritas respectivamente como escola "A" e "B" nesse artigo.

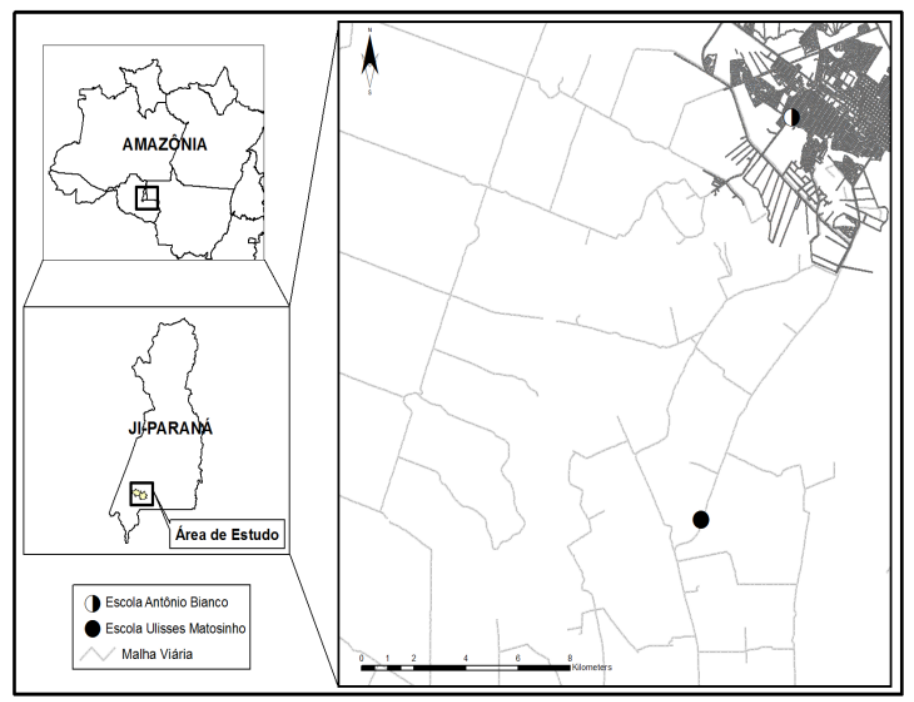

Figura 1: Localização das escolas no município de Ji-Paraná, RO. 


\section{Equipe e instituições}

Para cumprir com as demandas do projeto e atingir os objetivos propostos, contou-se com um grupo de atores capazes de executar as ações planejadas de maneira comprometida com os aspectos interdisciplinares inerentes a EA.

A equipe do projeto foi composta por alunos, técnicos e professores do curso de graduação em Engenharia Ambiental e Sanitária da UNIR/Campus JiParaná. Porém, para execução das atividades houve o apoio de gestores escolares, bem como de equipes pedagógicas, professores e alunos das escolas selecionadas, além da colaboração de técnicos de instituições parceiras que atuam no apoio e na disseminação de práticas de EA na região, como a Secretaria Municipal de Meio Ambiente (SEMEIA), a Entidade Autárquica de Assistência Técnica e Extensão Rural do Estado de Rondônia (EMATER/RO), e a Secretaria Municipal de Obras e Serviços Públicos (SEMOSP) da prefeitura Municipal de Ji-Paraná (RO).

\section{Abordagem Metodológica}

Para a realização das atividades foram empregadas as metodologias participativas, informativa, dialogada e perceptiva-descritiva, além de procedimentos transversais como princípios pedagógicos para a instrução do público-alvo, tal como determina a Lei no 9.795 que formaliza a Política Nacional de Educação Ambiental (BRASIL, 1999).

As metodologias participativas foram desenvolvidas pelos proponentes do projeto (professores e alunos do curso de graduação em Engenharia Ambiental e Sanitária) com o envolvimento dos gestores escolares, professores e alunos das escolas objeto de estudo, para que ambos realizassem um trabalho em comum (LATINI et al., 2018). Cabe mencionar que os métodos participativos estavam focados na valorização da opinião das pessoas, sendo essa afinidade essencial para a construção de novos conhecimentos na sociedade.

Tal abordagem foi determinante para o estabelecimento de uma relação de confiança, bem como estimular saberes em espaços interinstitucionais e democráticos (MORAIS; CALLOU, 2017), sobretudo, a partir de procedimentos alternativos que permitiram especiais vivências de sentimentos e percepções para que a coletividade pudesse refletir sobre suas práticas e/ou adequar as atitudes (QUEIROZ; COUTO, 2015).

\section{Apresentação do projeto e definição das atividades nas escolas}

Em ambas as unidades definidas para estudo, foi apresentado o projeto de extensão universitária aos dirigentes escolares, às equipes pedagógicas, assim como professores e alunos, permitindo aos envolvidos uma maior compreensão dos objetivos, desafios e oportunidades do projeto. 
Momentos de debate, estudo e reflexão sobre as atividades escolares e as ementas das disciplinas foram realizadas com os professores das matérias que integram os componentes curriculares das escolas, a fim de definir os temas das oficinas e palestras ministradas no decorrer do projeto. Sobre esta questão, é válido destacar que a seleção dos temas visando o ensino e a aprendizagem priorizaram os assuntos que estão próximos da realidade dos alunos (WEMTZ et al., 2011). Com base nisto e nos problemas ambientais identificados no entorno das escolas, foram estabelecidas as temáticas solo e água, fogo e queimadas e compostagem.

Nos encontros com as equipes pedagógicas e professores, também foram discutidas a importância de trabalhar a EA de forma transversal com o ensino, além de propor meios para utilizar o ambiente da horta escolar como laboratório didático alternativo, com o propósito de facilitar a compreensão dos conteúdos ministrados nas salas de aula (SOUZA et al., 2018).

Após a definição das demandas teóricas, foram organizadas e planejadas as atividades práticas, como: palestras, oficinas, capacitação da equipe do projeto, montagem dos canteiros para implantação das hortas, definição das espécies a serem cultivadas, época de plantio e colheita. Todos os procedimentos programados foram realizados entre março e dezembro de 2016. As ações envolveram os professores e alunos do $3^{\circ}$ ao $9^{\circ}$ ano na escola $A$, e da $6^{\underline{a}}$ a $9^{a}$ série, na escola $B$, bem como docentes e alunos da UNIR/Campus Ji-Paraná.

\section{Resultados e Discussão}

\section{Atividades com o corpo docente}

A EA é um dos instrumentos capazes de disseminar conhecimentos sobre o meio ambiente. Em vista disto, o presente projeto priorizou conscientizar e sensibilizar os professores a respeito das questões ambientais a partir do cotidiano escolar. Foram realizadas oficinas e palestras (Figuras $2 \mathrm{a}$ e $2 b$ ) com base no pluralismo de ideias e de acordo com a determinação da Política Nacional de Educação Ambiental, em especial, para que o corpo docente das escolas reavaliasse suas atitudes e valores acerca das questões ambientais e percebesse alternativas para desenvolver os conteúdos de cada disciplina.

Para tanto, foi realizado a construção de diálogos que deram subsídio para a percepção da importância da horta como laboratório didático e, assim, ampliar os diálogos relacionados com o meio ambiente nas escolas. Tais condutas possibilitaram mudanças de perspectivas, bem como oportunidades de aprendizado e novos significados para os professores, técnicos e alunos envolvidos nas ações. 

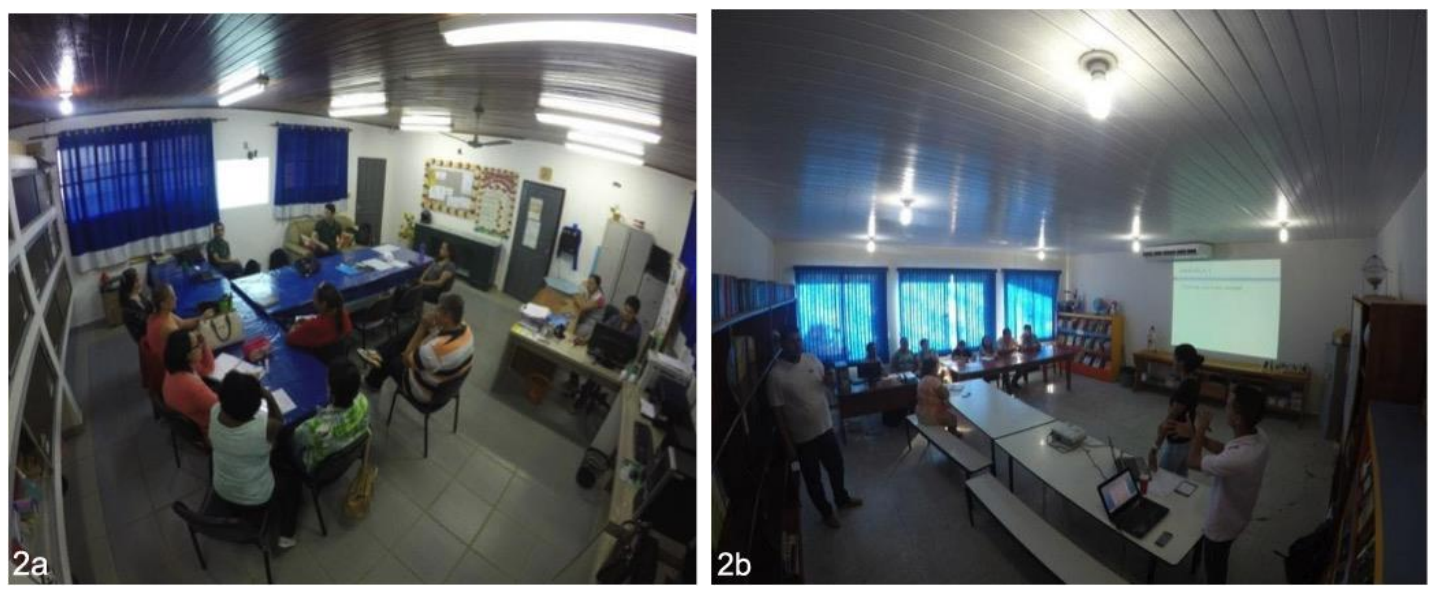

Figura 2: Oficinas e palestras com os docentes das Escolas A (2a) e B (2b).

No decorrer das ações foram abordados e discutidos a relevância da atuação dos professores no processo da EA, a partir das práticas interdisciplinares, onde eles traçaram métodos que favoreceram a compreensão e a importância da EA. Todavia, isto foi desenvolvido com prudência a fim de que os assuntos fossem contextualizados com o meio adjacente e pudessem ser debatidos de maneira atual e esclarecedora.

Neste contexto, o professor foi orientado a agir como um intermediador da aprendizagem e as técnicas a serem empregadas devem reconhecer a existência de uma forte dependência de sua atuação, especialmente para despertar o interesse dos alunos para que possam adquirir conhecimento sobre as questões ambientais (SOUZA et al., 2018).

Em vista disto, foi realçado os procedimentos de ensino da EA sob a ótica transversal, dando ênfase à produção de materiais, além de experiências práticas e culturais para serem vivenciadas fora da sala de aula. Estas atividades devem reconhecer os alunos como agentes ativos dentro do contexto que norteia a política ambiental (MINÉU et al., 2014).

Ademais, foram realizadas dinâmicas com os professores onde eles propuseram atividades relacionadas à EA com base na adaptação dos conteúdos das disciplinas que cada professor leciona, onde os professores conseguiram anexar os conteúdos das suas disciplinas com os eixos ambientais. Além disso, o corpo de professores das duas escolas passou a compreender a horta como um eixo capaz de englobar diversos aspectos, o que é de grande relevância para a formação dos alunos e também da própria comunidade escolar pelo aporte prático da transdisciplinaridade.

De maneira geral, as dinâmicas envolvendo os professores foram relevantes, visto que várias questões foram elucidadas e, a partir dessas atividades, obteve-se maior reconhecimento e apoio pelos demais servidores das escolas para a realização das ações do projeto. 


\section{Oficinas com os alunos:}

\section{Atividade sobre solo e água}

Essa atividade trabalhou distintos conceitos e experiências sobre a conservação do solo e da água, introduzindo termos como porosidade, umidade, formação dos solos, degradação dos solos, abundância da água, ciclo hidrológico e poluição da água (Figura 3a). Também foi abordado sobre o processo de infiltração da água no solo para a formação do lençol freático e destacada a relevância da vegetação para preservação do solo e da água. Uma demonstração foi realizada para elucidar as dúvidas e demonstrar o comportamento e a perda do quantitativo de solo pela ação da precipitação (simulada) em ambientes com presença de vegetação e sem vegetação (solo exposto).

Esta prática contribuiu para que os alunos compreendessem a importância da existência das florestas e da cobertura do solo para a manutenção e conservação dos recursos naturais, principalmente da água e do solo (Figura $3 \mathrm{~b}$ ). Na oficina foram apresentados os diferentes tipos de solos (Figura 3c), bem como a sua importância para as florestas e o cultivo de hortaliças. A oficina foi realizada no "Dia Nacional da Conservação do Solo" (15 de abril) e, além de instrumento educador teórico, teve como objetivo incentivar os alunos a mudarem suas práticas a respeito das atitudes que acarretam problemas para o solo e à água, destacando as consequências de suas ações e a importância da conservação desses recursos para a vida do homem. (Figura 3d).

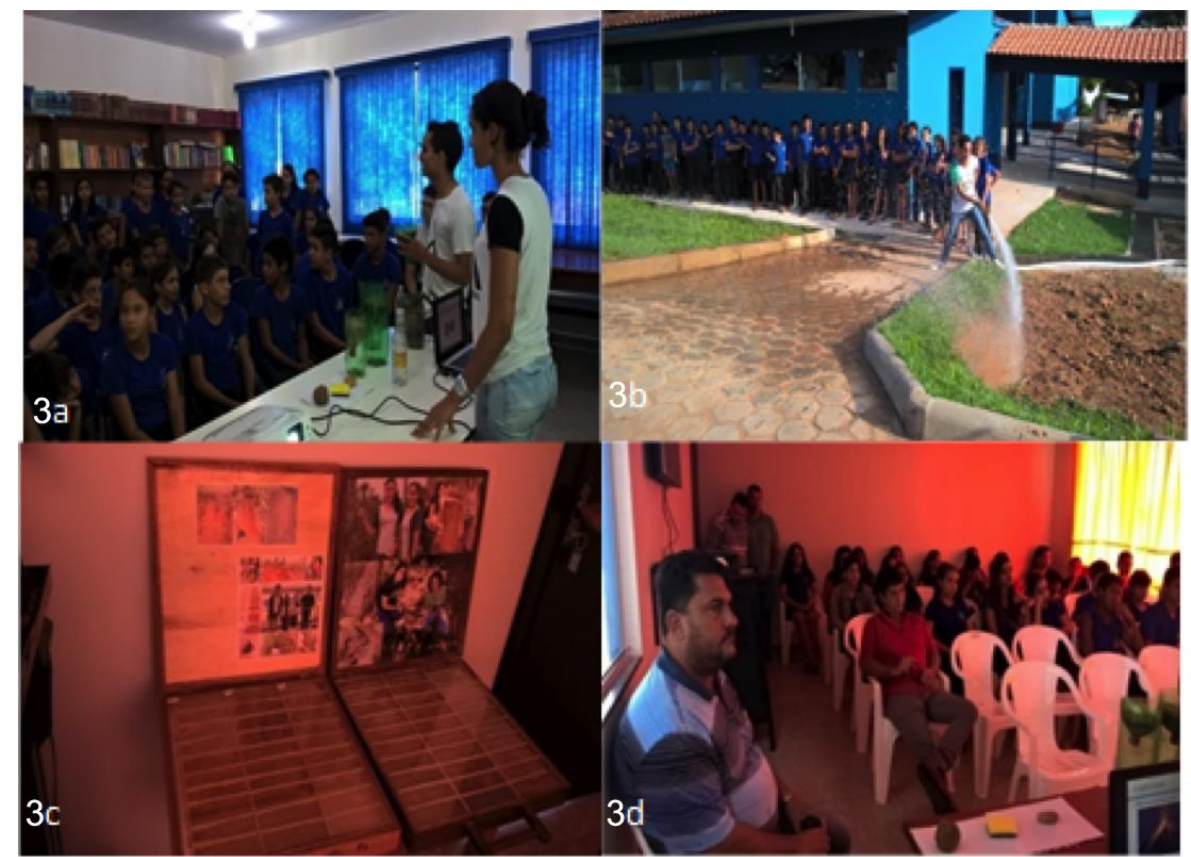

Figura 3: Atividades sobre solo e água. 


\section{Atividade sobre fogo e queimada}

O uso do fogo e queimadas como alternativa de controle de plantas indesejadas em áreas rurais e/ou na eliminação de resíduos domésticos em áreas urbanas, mesmo sendo reconhecidamente danosas a saúde humana e à natureza, ainda se configura como uma prática comum na região amazônica. Neste sentido e com a finalidade de destacar os conceitos sobre queimadas, expor suas consequências para a saúde humana e o meio ambiente, além de esclarecer os motivos que inviabilizam a sua prática, a ação visou promover a conscientização dos alunos levando-os a refletir sobre tais atitudes, bem como incentivando-os a compartilhar tais reflexões para deixarem de realizar queimadas em suas casas.

Em vista disso, questionou-se inicialmente para os alunos se eles sabiam 0 que eram queimadas. Em seguida foram enfatizadas as consequências dessa prática e apontadas várias justificativas para o seu impedimento, já que as queimadas provocam danos à saúde (como doenças respiratórias, alergias e náuseas), bem como a degradação do meio ambiente, com efeitos deletérios sobre a fauna, flora e atmosfera (OLIVEIRA et al., 2017; TORRES et al., 2018).

Além do mais, foram apresentados, descritos e exemplificados para os alunos, os principais impactos gerados na umidade do solo em decorrência do uso das queimadas, com o propósito de expor a relação entre causa e efeito, para o reconhecimento da existência de solos com aspectos erodidos, compactados e com baixos teores de nutrientes. Por fim, alertou-se sobre os perigos do descontrole do fogo para as propriedades vizinhas, florestas, entre outros ambientes.

\section{Atividade sobre compostagem}

Para que essa atividade fosse executada foi firmada uma parceria externa com a Entidade Autárquica de Assistência Técnica e Extensão Rural do Estado de Rondônia (EMATER/RO), com o intuito de capacitar a equipe do projeto para que posteriormente fosse possível compartilhar o conhecimento adquirido nas escolas.

A capacitação sobre compostagem para os professores, técnicos e alunos do projeto, foi feita através de ações teóricas e práticas (Figuras $4 a$ e $4 b)$. Durante as atividades, foram abordados os processos de decomposição da matéria orgânica e de qualidade do húmus, além das características dos resíduos e demais materiais a serem utilizados na compostagem, enfatizando 0 passo a passo para montagem das "leiras" de compostagem, para posterior aplicação nas escolas. 


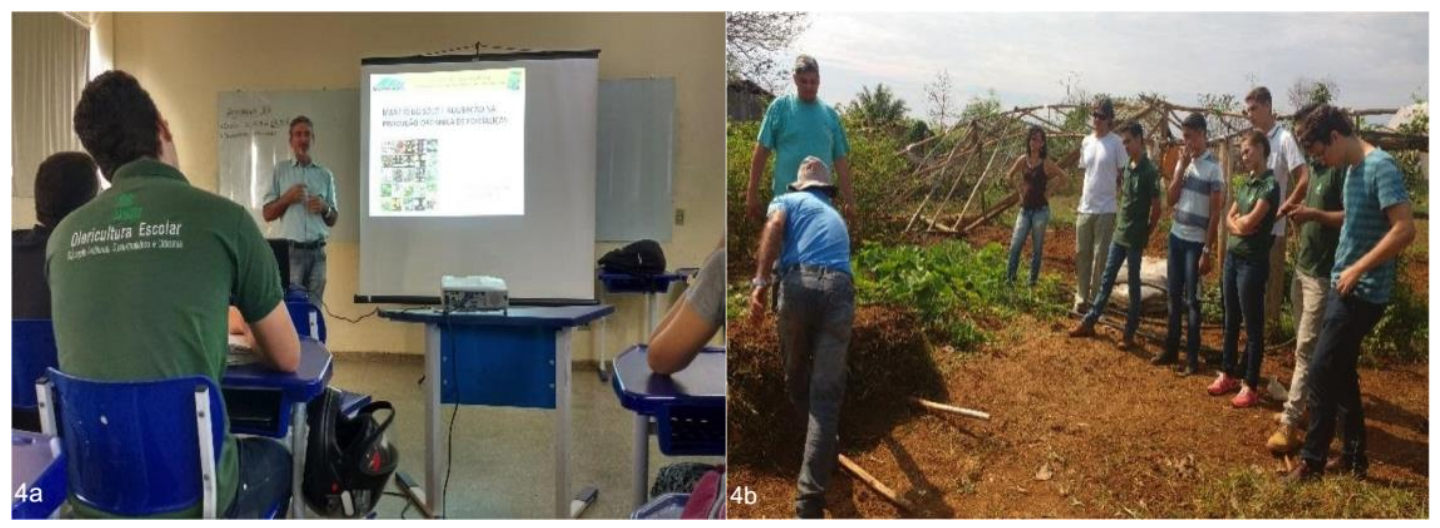

Figura 4: Capacitação da equipe do projeto com apoio da EMATER/RO, por meio de atividades teóricas (4a) e práticas (4b).

$\mathrm{Na}$ sequência disso, foi realizada uma introdução sobre fertilização orgânica e fertilização química para os alunos (Figura 5a). Entre os procedimentos práticos replicados nas escolas, foram construídas três leiras de compostagem utilizando os restos de alimentos da merenda escolar nas duas unidades (Figura 5b).

Durante o tratamento da compostagem foi enfatizado que esta prática se encontra em conformidade com a Política Nacional de Resíduos Sólidos, a qual visa estimular novas formas de gerenciamento dos resíduos, em especial para a transformação dos resíduos sólidos orgânicos - a exemplo dos restos da merenda escolar para a geração de um produto final denominado "composto" ou "adubo orgânico" através da decomposição biológica. Tal composto pôde ser utilizado na manutenção de hortas, viveiros e jardins, visto que a adubação orgânica contribui na tarefa de retorno dos nutrientes contidos nos resíduos orgânicos para o agroecossistema.

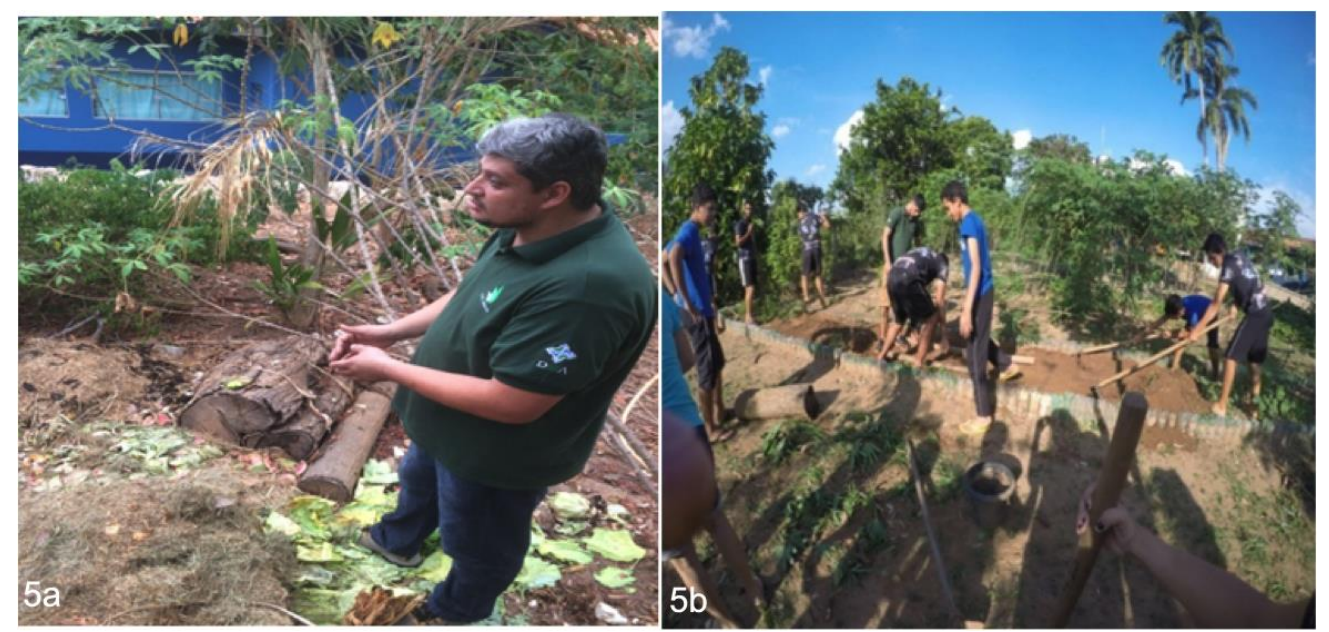

Figura 5: Atividades teórica (5a) e prática (5b) sobre compostagem com os alunos da Escola B. 


\section{Limpeza da área, reparo e montagem dos canteiros}

Essa ação foi proposta pelos professores durante a apresentação do projeto nas escolas e teve como objetivo trabalhar os conteúdos de matemática e EA de forma transversal. Em vista disso, foram desenvolvidas atividades para obtenção das dimensões dos espaços destinados à olericultura nas escolas. Esta ação foi utilizada como uma oportunidade para debater com os alunos o surgimento da necessidade de cálculos de medição e contagem na humanidade.

Nas atividades extraclasse foram apresentadas e explanadas as diferentes formas geométricas existentes na natureza, além dos conceitos de medidas, as unidades de medidas e a importância da padronização numérica para a matemática, vindo contribuir para o ensino da disciplina fora do contexto formal e assim aproximar o aprendizado do cotidiano, o qual é normalmente menos compreensível para o aluno quando visto apenas em sala de aula (CARVALHO et al., 2015).

$\mathrm{Na}$ área destinada à implantação da olericultura na Escola $\mathrm{A}$, existiam canteiros antigos feitos de tijolos, porém, sem possibilidade de uso para o plantio devido a presença de raízes de árvores que se desenvolveram no local. Por esta razão, optou-se em substituir os tijolos por materiais recicláveis. $\mathrm{E}$, a partir de garrafas pets trazidas pelos alunos (Figura 6a), foram produzidos cinco novos canteiros de pets e dois com pneus de caminhão.

Estas atividades foram realizadas com os alunos do $6^{\circ}$ ao $9^{\circ}$ ano (Figura $6 b)$ e a limpeza do local feita pelos servidores da Secretaria Municipal de Obras e Serviços Públicos (SEMOSP), da prefeitura de Ji-Paraná, cujo órgão era parceiro do projeto.
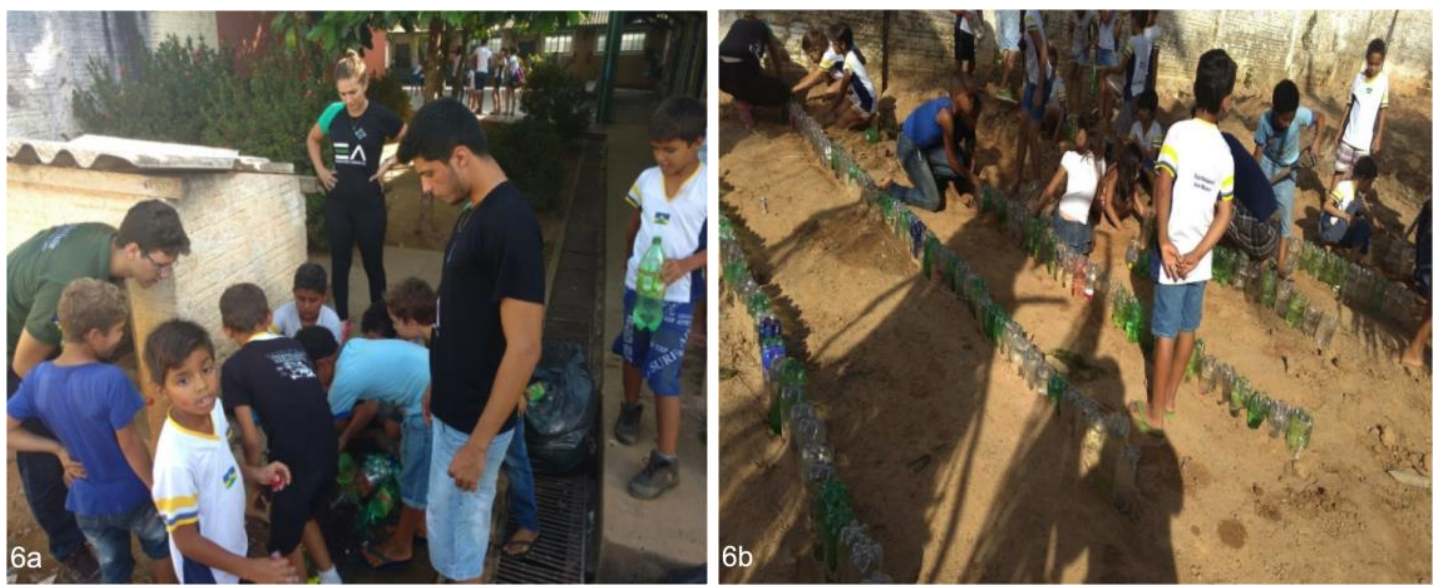

Figura 6: Canteiros feitos com garrafas pets trazidas pelos alunos. 


\section{Plantio e colheita}

Ambas as escolas contempladas com o projeto tinham áreas disponíveis para a implantação de horta e/ou pomar. Entretanto, ficou acordado com os gestores escolares que seriam implantadas hortas ao invés de pomares nas duas unidades de ensino, visto que ambas poderiam aproveitar a produção gerada nos cultivos para complementar a merenda fornecida aos alunos.

Nas Escolas A e B foram feitos mutirões com os alunos para limpar os ambientes destinados às hortas e, também, para a fixação de novas garrafas pets nos canteiros. Após essas etapas realizou-se o plantio de algumas hortaliças (Figura 7a) e a colheita de cheiro verde e mandioca (Figura 7b), anteriormente plantadas pelas cozinheiras da Escola B.
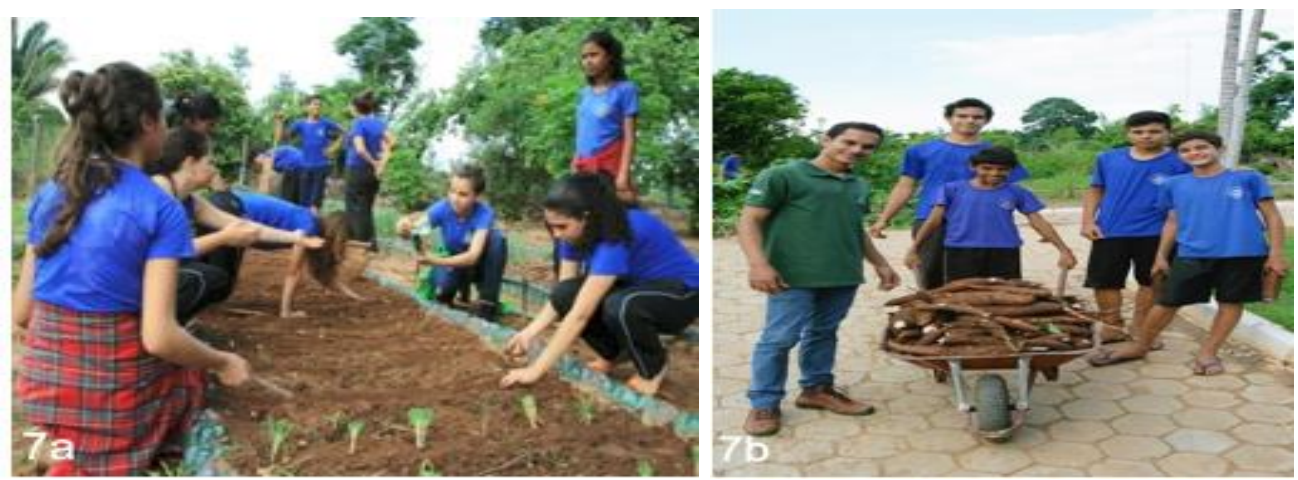

Figura 7: Plantio (7a) e colheita (7b) na Escola B.

As sementes e mudas utilizadas nas hortas das duas escolas foram doadas por meio da parceria com a Secretaria Municipal do Meio Ambiente (SEMEIA), do município de Ji-Paraná. As técnicas empregadas para o plantio foram ensinadas em sala de aula e durante as atividades práticas realizadas pela equipe do projeto (Figura 8a). O adubo depositado para melhorar a fertilidade do solo das hortas (Figura $8 \mathrm{~b}$ ) foram produzidos no processo de compostagem implantados nas escolas, onde os alunos puderam compreender na prática o que é um adubo orgânico e como é produzido.
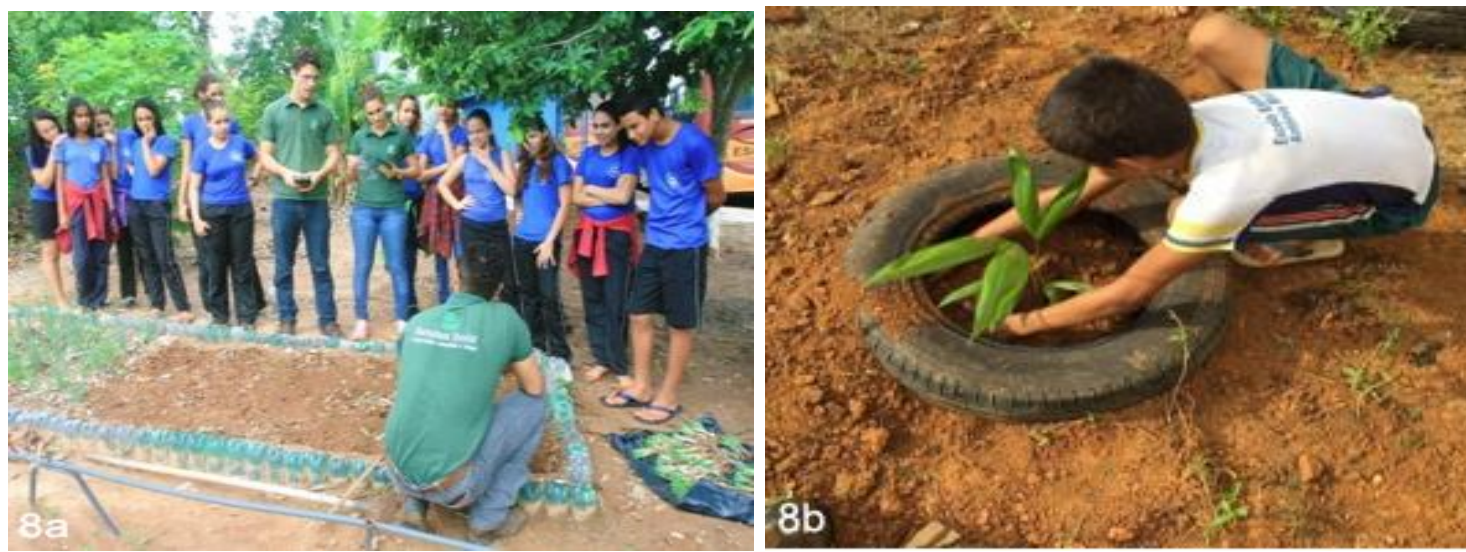

Figura 8: Técnicas de plantio (8a) e de adubação (8b) nas Escolas A e B.

Revbea, São Paulo, v.16, № 1: 378-392, 2021. 
Levando em conta os aspectos tratados, destaca-se que as duas escolas se empenharam para que o projeto fosse executado de maneira eficiente, no entanto, foi possível perceber uma diferença em relação a aceitação e facilidade de realização das atividades entre as escolas. Tal diferença possivelmente se deu porque a Escola B está inserida na zona rural do município de Ji-Paraná, onde as práticas do cotidiano dos alunos e de alguns professores estão mais relacionadas com as ações desempenhadas na horta escolar, fato que não ocorre na Escola $A$ localizada no perímetro urbano do município.

Outro fator que provavelmente influenciou na diferenciação dos resultados está relacionada com a facilidade de aceitação das ações propostas, especialmente sobre a organização das escolas em relação ao contexto local. Por esta razão, na Escola B houve maior envolvimento dos professores junto as atividades do projeto, sobretudo devido esta unidade desenvolver ações para estimular nos estudantes a educação associada com o meio ambiente, fato que não foi observado na Escola $A$ inserida na área urbana. Sobre tais aspectos, Cribb (2010) explicou que sem ocorrer a aceitação e o envolvimento de todos na promoção da EA não haverá melhorias no ensino.

Todavia, os estudantes das duas escolas deram muita importância ao processo educativo vinculado com o meio ambiente. Não obstante, ambas escolas carecem de alternativas que possibilitem maior planejamento para criar mecanismos que promovam a exposição de conhecimentos sobre as questões ambientais de maneira criativa, envolvente e continuada entre os atores englobados por elas. Análises semelhantes a estas foram descritas por Brito et al. (2016) e Souza et al. (2018), os quais relataram existir pouco envolvimento e desenvolvimento da EA no âmbito escolar, visto que este processo depende exclusivamente da vontade dos docentes para a sua implantação e execução.

Algo marcante observado e que merece destaque, foi o enorme interesse dos alunos nas atividades práticas de campo. Em vista disso, Alves (2004) e Cribb (2010) discorreram que a realidade socioambiental a qual os estudantes são inseridos influenciam no seu interesse e, consequentemente, na sua dinâmica de aprendizado. Além do mais, estes fatores podem estar associados a prática da transdisciplinaridade e de superação da fragmentação do conhecimento, anteriormente limitada à compreensão por meio de apenas uma disciplina ministrada em sala de aula.

Os registros fotográficos feitos durante a realização do projeto foram apresentados aos gestores das escolas, sobretudo para demonstrar o que foi executado nas unidades de ensino e auxiliar no entendimento dos temas estudados. Esta conduta, segundo Faria et al. (2016), tem função didádicopedagógica e são referências de espaço(s), objeto(s), sujeito(s) e ação(ões), o que os torna apropriados para ilustrar o interesse que os alunos apresentaram no engajamento e participação das atividades. 
Em virtude das questões levantadas com as atividades do projeto, observa-se realidades bem distintas. Sobre isto, é válido mencionar que o trabalho necessita de um tempo maior de estudo no que se refere a EA, sobretudo para aumentar o nível de cooperação entre os alunos e o senso de responsabilidade a partir de práticas simples no âmbito escolar, a exemplo da implantação de hortas orgânicas para tratar da importância de se ter um ambiente ecologicamente equilibrado e capaz de melhorar a saúde da presente e futuras gerações.

\section{Conclusão}

A ampliação de espaços alternativos de aprendizagem a partir de projetos de extensão universitária traz benefícios eficientes no âmbito escolar, porém, ainda está longe do ideal, o que evidencia a necessidade de um engajamento maior entre o sistema educacional e as políticas públicas brasileiras.

Todavia, é válido destacar a urgência de conceber novas maneiras de criar conhecimentos e aprendizados nas escolas públicas do Brasil, especialmente para propiciar habilidades, atitudes e valores capazes de promover melhorias em relação as questões ambientais, sobretudo nos municípios da Amazônia Legal.

Por fim, conclui-se que a implantação de hortas escolares pode ser vista como uma ferramenta alternativa para trabalhar os conhecimentos de forma integrada com o meio ambiente, permitindo que os alunos adquiriram novos entendimentos a respeito da temática ambiental e assim viabilizar o surgimento de uma coletividade mais harmônica, capaz de tratar os aspectos ambientais, sociais e econômicos de modo sustentável.

\section{Agradecimentos}

À Pró-Reitoria de Cultura, Extensão e Assuntos Estudantis (PROCEA); ao Departamento de Engenharia Ambiental e Sanitária (DEAS) da Fundação Universidade Federal de Rondônia (UNIR), além das escolas e instituições descritas nesse trabalho que possibilitaram a execução do projeto.

\section{Referências}

ANDRADE, D. F. Implementação da Educação Ambiental em escolas: uma reflexão. Revista Eletrônica do Mestrado em Educação Ambiental, v. 4, p. 1-9, 2000.

BRASIL, RESOLUÇÃO № 2, DE 15 DE JUNHO DE 2012. Estabelece as Diretrizes Curriculares Nacionais para a Educação Ambiental. DOU, 2012.

BRASIL. Lei n. 12.305, de 2 de agosto de 2010. Institui a Política Nacional de Resíduos Sólidos; altera a Lei №. 9.605, de 12 de fevereiro de 1998; e dá outras providências. DOU, 2010 
BRASIL. Lei n. 7.725, de 27 de abril de 1999. Dispõe sobre a Educação Ambiental, institui a Política Nacional do Meio Ambiente e dá outras providências. DOU, 1999.

BRITO, V.L.T.; ARAÚJO, M.F.V.; MACHADO, R.R.B.; MORAES, L.A. Importância da Educação Ambiental e meio ambiente na escola: uma percepção da realidade na escola municipal Comendador Cortez em Parnaíba (PI). Revista Brasileira de Educação Ambiental, v. 11, n. 2, p. 22-42, 2016.

CARVALHO, A.M.P.; REIS, I.; NORI, M.C. Problemas na educação matemática do ensino fundamental por fatores de dislexia e discalculia. Vida de Ensino. v. 02, n. 8, p. 66-72, 2010.

CRIBB, S. L. S. P. Contribuições da Educação Ambiental e Horta Escolar na Promoção de Melhorias ao Ensino, à Saúde e ao Ambiente. Revista Eletrônica do Mestrado Profissional em Ensino de Ciências da Saúde e do Ambiente, v. 3, n. 1p. 42-60, 2010.

DIAS, G.F. Educação Ambiental: princípios e práticas. São Paulo: Gaia, 1992.

FARIA, F. C.; CUNHA, M. B. 'Olha o passarinho!' A fotografia no Ensino de Ciências. Acta Scientiarum. Human and Social Sciences, v. 38, n. 1, p. 57-64, 24 jun. 2016.

HENNING, I.D.; LENARDÃO, E. Processo pedagógico envolvendo a olericultura: articulação entre a educação profissional e o ensino fundamental - a horta escolar em foco. Os desafios da escola pública paranaense na perspectiva do professor PDE, Curitiba, Secretaria Estadual de Educação, 2016.

JACOBI, P. Educação Ambiental, cidadania e sustentabilidade. Cadernos de Pesquisa, n. 118, p. 189-203, 2003.

LATINI, R. M.; OLIVEIRA, L.R.; CANESIN, F.P.; SANTOS, M.B.P.; FERREIRA, P.E. Contribuição de metodologias participativas como prática mediadora em educação química e ambiental. Revista Electrônica de Enseñanza de las Ciencias. v. 17, n. 2, p. 290-308, 2018.

MACEDO, E.; OLIVEIRA, I.N.B.; MANHÃES, L.C.; ALVES, N. (org.). Criar currículo no cotidiano. 3 ed. São Paulo: Cortez Editora, 104 p., 2004.

MINÉU, H.F.S.; TEIXEIRA, R.A.; COLESANTI, M.M. A Educação Ambiental no currículo escolar do ensino média da rede estadual de Minas Gerais. Ambiente \& Educação, v. 19, n. 2, p. 18-38, 2014.

MORAIS, J. A. de; CALLOU, A. B. F. Metodologias participativas e desenvolvimento local: a experiência do Projeto Dom Hélder Câmara no assentamento Moacir Lucena. Interações (Campo Grande), v. 18, n. 1, p.165177, 2017.

OLIVEIRA, A.L.S.; NERO, M.A.; JÚNIOR, J.R.T.; CANDEIAS, A.L.B.; NÓBREGA, R.A.A. Comparação e validação da modelagem espacial de riscos de incêndios considerando diferentes métodos de predição. BCG - Bulletin of Geodetic Sciences, v. 23, ํㅡ 4, p. 556-577, 2017. 
PITANGA, A.F. A Educação Ambiental Crítica Como Fundamentação Teórica da Pedagogia 4Cs: Criticidade, Cientificidade, Colaboração e Criatividade. Revista Eletrônica do Mestrado em Educação Ambiental. v. 36, n. 3, p. $102-$ 118, 2019.

QUEIROZ, A. G.; COUTO, A. C. P. Metodologia participativa, subjetivamente individual e social: facilitação de reuniões de moradores em Residências Terapêuticas. Pesquisas e Práticas Psicossociais. v. 10, n. 1, p. 171-178 , 2015.

ROCHA, S.A.D.; ADAME, A. Uma visão interdisciplinar da realidade: inclusão da Educação Ambiental nas escolas estaduais e municipais no município de Juína, Estado de Mato Grosso. IURISPRUDENTIA: Revista da Faculdade de Direito da Ajes, v. 2, n. 4, p. 99 - 117, 2013.

RODRIGUES, F.C.C.; PALHETA, R.T.M. Educação Ambiental e interdisciplinaridade: a importância da água na vida dos ribeirinhos da ilha das onças (furo conceição), Barcarena, Pará, Brasil. Ambiente e Educação. v. 24, n. 2, p. 310-330, 2019.

ROSA, M.C.P.; ROSA, M.B. Uma proposta de atividades práticas em Educação Ambiental para o ensino fundamental. Monografias Ambientais. v.1, n.1, p. 108-121, 2010. DOI: https://doi.org/10.5902/223613082294

SANTO, T.L.S.S.; MUTIM, A.L.B. Educação Ambiental e políticas públicas: foco de intervenção no sistema educacional. Revista Sergipana de Educação Ambiental. v. 7, n. 2, p. 26-33, 2019.

SILVA, R.A.; TORRES, M.B.R. Cuidado ambiental na agricultura familiar. Revista Eletrônica do mestrado em Educação Ambiental. v. 36, n. 3, p. 178197, 2019.

SOUZA, N.F.C.; ANDRADE, N.L.R.; RIBEIRO, J.G.S.; GOMES, J.C.; OROZCO, M.M.D.; PEREIRA, E.S. Práticas em Educação Ambiental voltadas à implementação do sistema de esgotamento sanitário de Presidente Médici. Revista Brasileira de Educação Ambiental, v.14, n.1, p. 339-361, 2019.

SOUZA, W. AGUIAR, R.G. Educação Ambiental em duas escolas localizadas no entorno da Reserva Biológica do Jaru - Amazônia Ocidental. Revista Brasileira de Educação Ambiental, v. 13, n. 1, p. 172-191, 2018.

TORRES, F.T.P.; TORRES, C.M.M.E.; LIMA, G.S.; MARTINS, S.V.; MENDES, A.E.O.; PADOVANI, M.T.; SIQUEIRA, R.G.; MOREIRA, G.F.; VALVERDE, S.R. Análise do perfil dos incêndios florestais no Parque Estadual da Serra do Brigadeiro e entorno (MG). Ciência Florestal, v. 28, n.3, p. 1008-1021, 2018.

WENTZ, F.M.A.; NISHIJIMA, T. A Educação Ambiental como meio de ação nas atividades agrícolas para preservação dos solos e da água nas comunidades rurais do município de Santo Ângelo - RS. Revista Eletrônica em Gestão, Educação e Tecnologia Ambiental. v.4, n.4, p. 558 - 571, 2011. 